\title{
Magnetic resonance susceptibility weighted imaging in neurosurgery: current applications and future perspectives
}

\author{
*Antonio Di leva, MD, PhD, ${ }^{1}$ Timothy Lam, BSc, ${ }^{1}$ Paula Alcaide-Leon, MD, ${ }^{2}$ Aditya Bharatha, MD, ${ }^{2}$ \\ Walter Montanera, MD, ${ }^{2}$ and Michael D. Cusimano, MD, PhD ${ }^{1}$
}

'Division of Neurosurgery, Department of Surgery; and 'Division of Neuroradiology, Department of Radiology, St. Michael's Hospital, University of Toronto, Ontario, Canada

\begin{abstract}
Susceptibility weighted imaging (SWI) is a relatively new imaging technique. Its high sensitivity to hemorrhagic components and ability to depict microvasculature by means of susceptibility effects within the veins allow for the accurate detection, grading, and monitoring of brain tumors. This imaging modality can also detect changes in blood flow to monitor stroke recovery and reveal specific subtypes of vascular malformations. In addition, small punctate lesions can be demonstrated with SWI, suggesting diffuse axonal injury, and the location of these lesions can help predict neurological outcome in patients. This imaging technique is also beneficial for applications in functional neurosurgery given its ability to clearly depict and differentiate deep midbrain nuclei and close submillimeter veins, both of which are necessary for presurgical planning of deep brain stimulation. By exploiting the magnetic susceptibilities of substances within the body, such as deoxyhemoglobin, calcium, and iron, SWI can clearly visualize the vasculature and hemorrhagic components even without the use of contrast agents. The high sensitivity of SWI relative to other imaging techniques in showing tumor vasculature and microhemorrhages suggests that it is an effective imaging modality that provides additional information not shown using conventional MRI. Despite SWl's clinical advantages, its implementation in MRI protocols is still far from consistent in clinical usage. To develop a deeper appreciation for SWI, the authors here review the clinical applications in 4 major fields of neurosurgery: neurooncology, vascular neurosurgery, neurotraumatology, and functional neurosurgery. Finally, they address the limitations of and future perspectives on SWI in neurosurgery.

http://thejns.org/doi/abs/10.3171/2015.1.JNS142349
\end{abstract}

KEY WORDS brain tumors; vascular neurosurgery; neurotrauma; functional neurosurgery; MRI; neuroradiology; SWl; susceptibility weighted imaging; diagnostic and operative techniques

$\mathrm{T}$ HE initial development of MR venography by Reichenbach et al..$^{90}$ laid the foundation for Haacke et al. ${ }^{42}$ to apply the principles of MR venography in conventional MRI for broader usage in clinical and research settings. By utilizing magnitude and phase information, both of which are normally acquired from conventional MRI data, susceptibility weighted imaging (SWI) has an enhanced ability to detect microhemorrhages ${ }^{4,12,26}$ and microvasculature..$^{26,27,41,92}$ It is a highly sensitive imaging modality able to depict magnetic substances, such as deoxygenated hemoglobin, with high contrast ${ }^{42}$ and to help investigate neurological diseases, ${ }^{82}$ grade tumors,${ }^{25,63}$ and assist in determining treatment or prognosis. ${ }^{18,26,37,70,71,115}$

Over the past years, the SWI technique has found applications in the different fields of neurosurgery, namely neurooncology, vascular neurosurgery, neurotraumatol-

ABBREVIATIONS AVM = arteriovenous malformation; $\mathrm{CCM}=$ cerebral cavernous malformation; $\mathrm{CMB}=$ cerebral microbleed; $\mathrm{CVS}=$ cortical vessel sign; $\mathrm{DAI}=$ diffuse axonal injury; DBS = deep brain stimulation; DWI = diffusion-weighted imaging; GBM = glioblastoma multiforme; GCS = Glasgow Coma Scale; GPe = external globus pallidus; GPi = internal GP; GRE = gradient-recalled echo; ITSS = intratumoral susceptibility signal; $m \mathrm{mP}=$ minimum intensity projection; MRA = MR angiography; MS = multiple sclerosis; $\mathrm{PD}=$ proton density; $\mathrm{PQ}=$ percentagewise quantification; $\mathrm{PWI}=$ perfusion-weighted imaging; $\mathrm{SN}=$ substantia nigra; $\mathrm{STN}=$ subthalamic nucleus; $\mathrm{SWI}=$ susceptibility weighted imaging; $\mathrm{TBI}=$ traumatic brain injury; VM = vascular malformation.

SUBMITTED October 13, 2014. ACCEPTED January 12, 2015.

INCLUDE WHEN CITING Published online July 24, 2015; DOI: 10.3171/2015.1.JNS142349.

DISCLOSURE The authors report no conflict of interest concerning the materials or methods used in this paper or the findings specified in this paper.

* Dr. Di leva and Mr. Lam contributed equally to this work. 
ogy, and functional neurosurgery. We here address SWI's current and future applications to make it more accessible to a broader audience of neurosurgeons.

\section{Technical Aspects of SWI}

\section{T2* Gradient-Recalled Echo}

Signal intensity on the MR image is determined by 3 basic parameters: 1) proton density (PD), 2) T1 relaxation time, and 3) T2 relaxation time. The T1 (longitudinal) and T2 (transverse) relaxation times define the way protons revert back to their resting states after the initial radiofrequency pulse.

\section{Susceptibility Weighted Imaging}

Susceptibility weighted imaging is a 3D gradient-recalled echo (GRE) sequence that was originally developed for MR venography by exploiting the blood oxygen level-dependent (BOLD) effect and using refined phase information for contrast enhancement in MR images. ${ }^{41,90}$ By extension, SWI involves the combining of magnitude and filtered phase data for further postprocessing in developing minimum intensity projection (mIP) images to depict smaller hemorrhages not seen with $\mathrm{T} 2 *$ imaging (Fig. 1). ${ }^{16,42}$ Figure 2 provides a schematic representation of the process of generating an SW image. Table 1 provides a glossary of technical terms used in the production of SW images.

Susceptibility weighted imaging has been tested at various magnetic fields, including $1.5,3$, and $7 \mathrm{~T}$. Higher magnetic fields accentuate magnetic susceptibility effects and hence produce SW images with a higher signal-to-
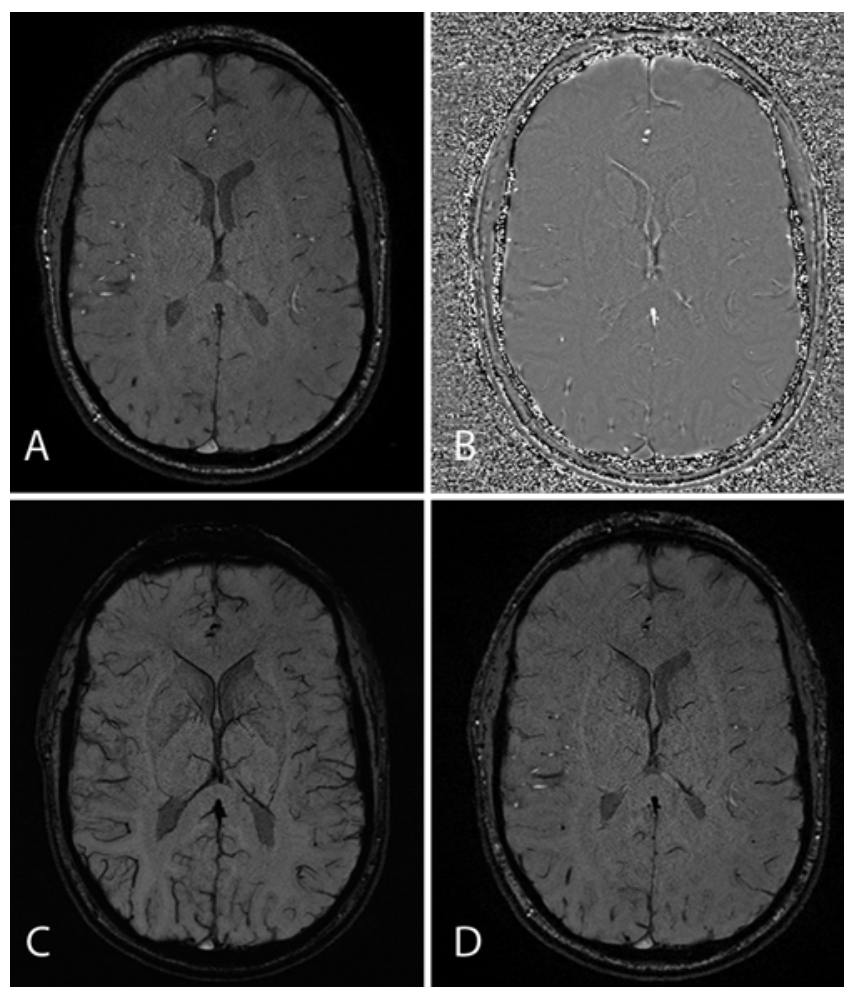

FIG. 1. Sets of images provided on SWI studies. A: Magnitude. B: Filtered phase. C: Minimum intensity projection reformat. D: SWI. noise ratio, thereby allowing for better visualization of the fine details in brain structures, ${ }^{73}$ tumors ${ }^{77}$ and deep and/or smaller vessels. ${ }^{27,77}$ However, ultrahigh field strengths such as $>7 \mathrm{~T}^{\text {in }} \mathrm{SWI}^{27}$ may distort the size of brain structures in regions characterized by high iron concentrations. ${ }^{73}$ Nonetheless, phase images can be used for differentiating between diamagnetic (that is, calcium) and paramagnetic substances (that is, deoxyhemoglobin, hemosiderin, and ferritin). ${ }^{13}$

\section{Literature Review Methods}

Using articles published in the PubMed database, we reviewed the existing SWI literature (Fig. 3). Publication years for all SWI articles ranged from May 2003 to December 2014. All reviewed articles were in English or were English summaries. The main key words for the search were as follows: 1) susceptibility weighed imaging or magnetic susceptibility; 2) magnetic resonance imaging or gradient recalled echo; 3) neuroradiology or neurosurgery studies. Inclusion criteria were as follows: 1) studies with human participants of any age group and 2) studies involving SWI at any magnetic field strength. Exclusion criteria involved contrast-enhanced SWI or dynamic susceptibility contrast-enhanced perfusion MRI. We selected and reviewed 29 articles in neurooncology, 21 articles in vascular neurosurgery, 17 articles in neurotraumatology, and 14 articles in functional neurosurgery.

\section{SWI in Neurooncology}

Preliminary research has involved examining the role of SWI as part of the imaging protocol to better detect and/or follow up on cerebral neoplasms. . $2,23,25,26,30,37,47,60,63$, $65,67,68,70-72,79,81,83,84,86,87,89,92,98,112,115,117,118$

\section{Detecting and Diagnosing Brain Tumors}

Numerous studies have shown that SWI is more sensitive than conventional MRI, including T1, 37,63,92 contrast-enhanced $\mathrm{T} 1,{ }^{63,92,117} \mathrm{~T} 2,{ }^{63,92,98} \mathrm{~T} 2{ }^{6}{ }^{65,117}$ FLAIR, ${ }^{63,92}$ PD-weighted, ${ }^{92}$ and diffusion-weighted imaging (DWI) ${ }^{92}$ in detecting vasculature, internal architecture, or hemorrhage in tumors (Figs. 4 and 5). Small vessels within low-grade gliomas, such as astrocytoma, can be depicted with SWI, ${ }^{63}$ and complex tumor vasculature can be found in high-grade gliomas, such as glioblastoma multiforme $(\mathrm{GBM}){ }^{25}$ In each case, the additional information helps in tumor grading, ${ }^{25,63}$ which can support neurosurgeons in diagnosis and therapeutic management.

In addition to tumor vasculature, the presence of calcification is important for the clinical diagnosis of brain tumors. Studies have reported that calcification in cerebral neoplasms is correlated with longer patient survival and better prognosis than those for tumors lacking calcification. ${ }^{54,75,78,81,118}$ Although CT is typically used to reveal calcification, ${ }^{34} \mathrm{SWI}$ can effectively demonstrate intratumoral calcification as well, 23,70,76,112,118 with hypointensity seen on SW images, which correlates with CT findings (Fig. 4). ${ }^{76,112,118}$

In cases in which tumors ${ }^{67,84,86}$ or medical conditions ${ }^{68,98}$ present similar imaging findings, SWI can help in the dif- 
TABLE 1. Glossary of SWI terminology for the production of SW images*

\begin{tabular}{|c|c|}
\hline SWI Term & Definition \\
\hline Magnitude image & $\begin{array}{l}\text { Imaging data that measures the amount of time protons take in order to revert back to its original position in the static magnetic } \\
\text { field after application of a radiofrequency pulse. }\end{array}$ \\
\hline Phase image & $\begin{array}{l}\text { Imaging data that measures proton flow and provides information on the susceptibility differences among tissues. Raw phase } \\
\text { information is not typically used in conventional MRI due to numerous unwanted phase artefacts. }\end{array}$ \\
\hline Phase mask & $\begin{array}{l}\text { An algorithm removing unwanted pixels possessing a set range of phase values in the magnitude image in order to enhance } \\
\text { the contrast within the magnitude image. }\end{array}$ \\
\hline High pass filter & $\begin{array}{l}\text { An imaging method to remove the low spatial frequency information within phase images. Application of a high pass filter will } \\
\text { generate a filtered phase image that can be combined with a magnitude image to form a SW image. }\end{array}$ \\
\hline Susceptibility effects & $\begin{array}{l}\text { A phenomenon describing substances that elicit magnetic properties when placed in an external magnetic field, and thereby } \\
\text { contribute to data collected in the magnitude and phase images. }\end{array}$ \\
\hline $\mathrm{mIP}$ & $\begin{array}{l}\text { A method to visualize SW data by combining four or more adjacent SW images for easier depiction of vessel connectivity and } \\
\text { hemorrhagic components with the presence of hypointense signals. }\end{array}$ \\
\hline Diamagnetic & $\begin{array}{l}\text { A property to describe materials that contain atoms that are weakly magnetic, thereby producing a hyperintense signal on SW } \\
\text { images that appear brighter than surrounding tissue. }\end{array}$ \\
\hline Paramagnetic & $\begin{array}{l}\text { A property to describe materials that contain atoms that are strongly magnetic, thereby producing a hypointense signal on SW } \\
\text { images that appears darker than surrounding tissue. }\end{array}$ \\
\hline
\end{tabular}

* See Haacke et al., 2009. ${ }^{41}$

ferential diagnosis. For example, SWI can help differentiate between brain abscess and necrotic GBM; a dual hypointense rim sign appears for the brain abscess (Fig. 6) but not for the GBM. ${ }^{30,98}$ In more complex cases, Lou et al. ${ }^{67,68}$ reported that SWI can detect and differentiate basal ganglia germinoma from subacute lacunar infarct. Currently, some researches are distinguishing brain tumors from multiple sclerosis (MS) plaques by using SWI. Haacke et al. ${ }^{40}$ reported on the effectiveness of SWI in detecting iron depos- its in MS lesions. SWI could differentiate the vessels from MS lesions by using mIP images to show the continuity of vessels passing through the lesion..$^{40}$ The ability of SWI to visualize regions of iron deposition is significant since iron, specifically hemosiderin, is found in the same regions where MS plaques are found. ${ }^{19,35,104}$ Although hemorrhagic tumors can also form iron deposits within brain parenchyma, MS plaques differ significantly from hemorrhagic tumors in their appearance on SW images given that hem-

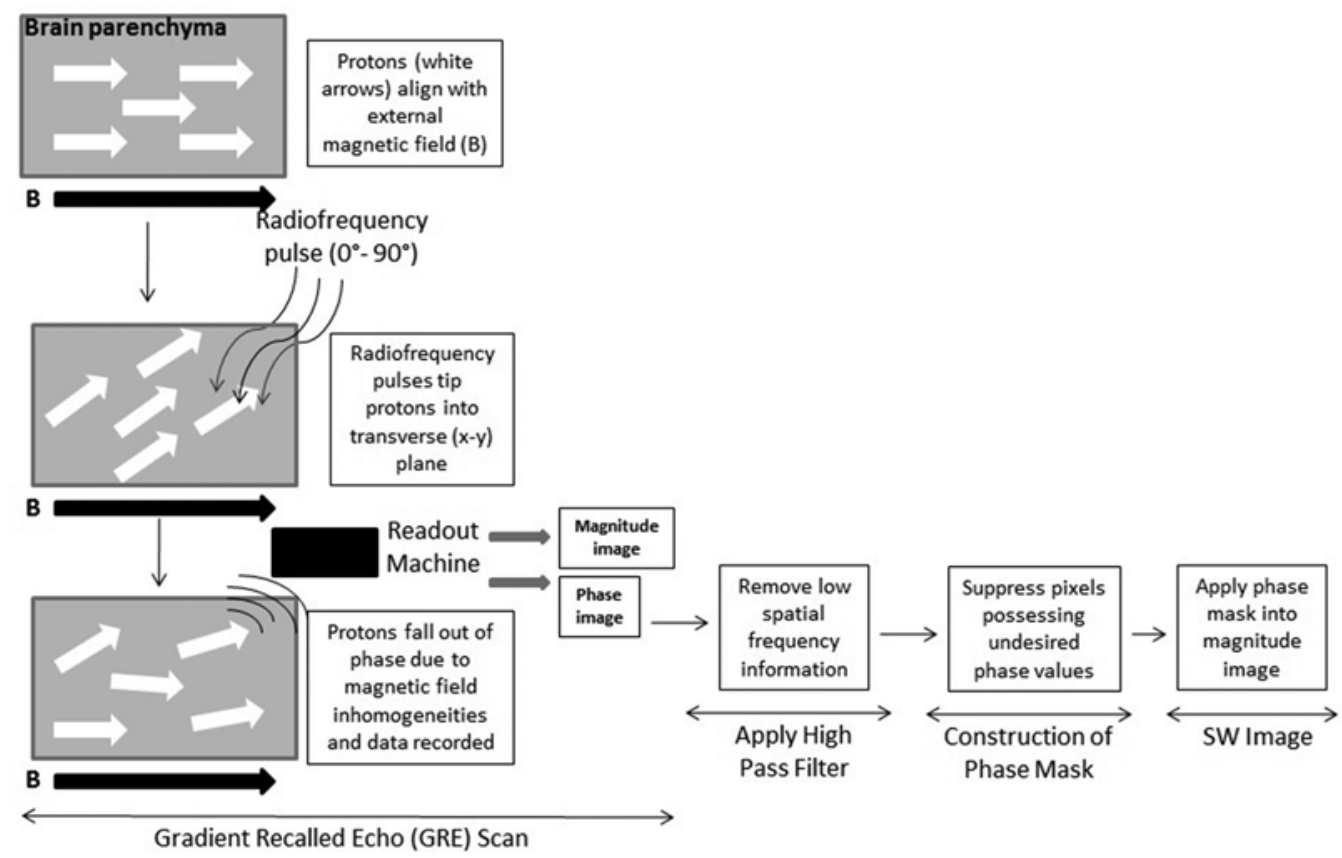

FIG. 2. Schematic for the creation of SW images. 1) Application of external magnetic field aligns protons in brain parenchyma in a uniform direction; 2) magnetic coil emits radiofrequency pulses to tip protons into the transverse (x-y) plane; 3) protons will fall out of phase with each other because of magnetic field inhomogeneities; 4) dephasing gradient is applied to first section of readout gradient to strengthen readout signal; 5) magnitude and phase images created; 6) phase image undergoes postprocessing with application of high pass filter and construction of phase mask; and 7) phase mask is multiplied into magnitude image to form SW image with heightened contrast. 


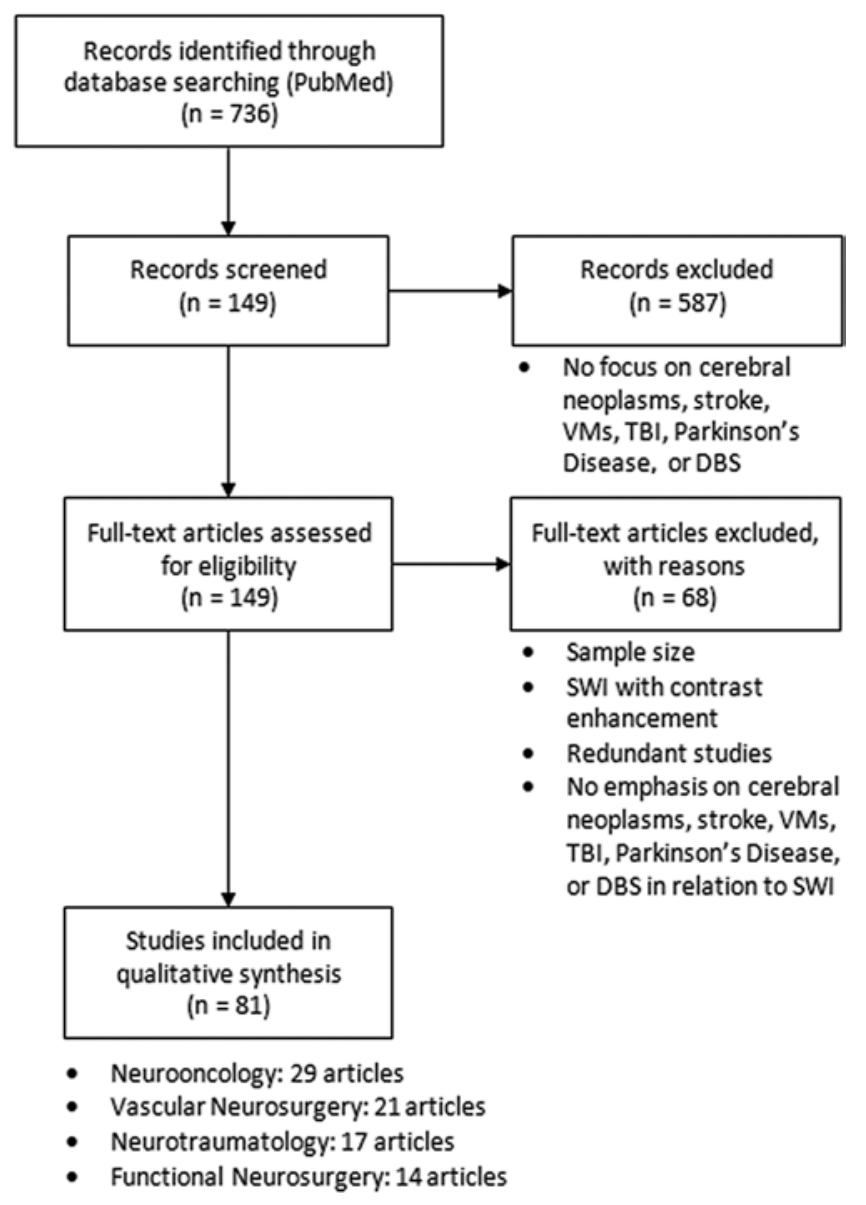

FIG. 3. Flowchart displaying search strategy and article selection.

orrhagic components would appear as hypointense foci, ${ }^{100}$ whereas MS plaques would appear with veins penetrating these plaques ${ }^{36}$ and less prominent venous vasculature visible around the MS lesion. ${ }^{11}$

A few studies have documented the ability of SWI to detect brain metastases..$^{84,89,92,117}$ In particular, percentagewise quantification (PQ) has been suggested to help distinguish different brain metastases, which represents a more objective technique in which dot-like or linear lesions on SWI are analyzed. Unfortunately, PQ does not consider the distribution and morphology of lesions found on SW images, which could provide additional information ${ }^{89}$ nor can PQ differentiate between breast carcinoma and bronchial carcinoma, which raises questions about the sensitivity of this technique.

Overall, a major limitation of MRI is that it can only be used for brain tumor detection and not diagnosis since biopsy or histological analysis must be performed in addition to MRI for an accurate diagnosis. ${ }^{8}$ Although research concerning SWI and histopathology is small, the SWI findings correlate well with histopathological results. ${ }^{37,63,92,115}$ Thus, SWI findings may hold some degree of diagnostic value since lesions seen within tumor boundaries indicate microvasculature and hemorrhagic components verified from pathology.

Aside from its ability to detect tumor characteristics, SWI has been used to objectively grade brain tumors, al-
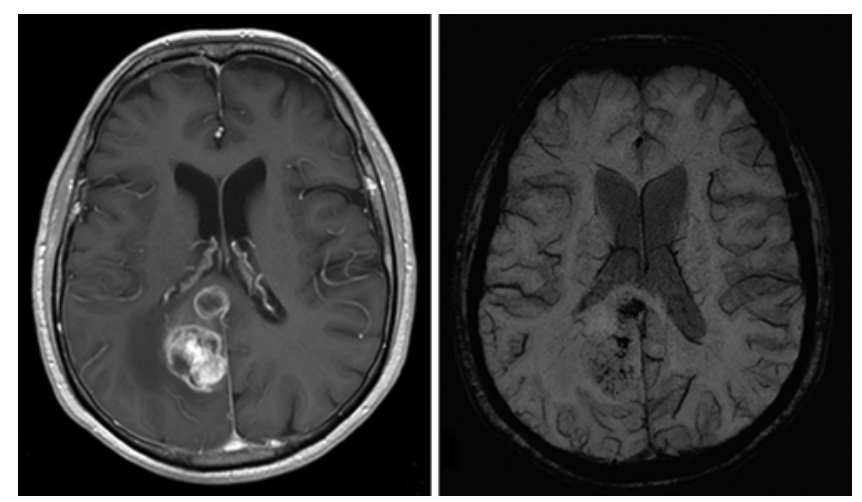

FIG. 4. Images obtained in a patient with Grade IV glial tumor (GBM). Axial T1-weighted sequence after Gd administration shows enhancing lesions with central areas of necrosis (left). SW image with mIP reformat demonstrates multiple hemorrhagic foci as well as linear thin vascular structures within the lesions (right).

though the methods in which it was used in grading has varied significantly between studies. Park et al. ${ }^{83}$ developed a semiquantitative method of grading cerebral neoplasms using intratumoral susceptibility signals (ITSSs), which are hypointense dot-like or linear structures within tumor boundaries on SWI. Grading is determined by the number of ITSSs depicted within the tumor. ${ }^{83}$ ITSSs can differentiate lymphomas from high-grade gliomas, with GBMs producing more prominent ITSSs. ${ }^{60,84,86}$ However, ITSSs are not as well suited for low-grade gliomas as they are for higher-grade gliomas, ${ }^{83,84}$ and hypointensity levels vary between different tumor types, such as GBM and anaplastic astrocytoma ${ }^{83}$ More importantly, identification of an ITSS is a subjective measure based on the discretion of the neuroradiologist.

Hori et al. ${ }^{47}$ described a scheme in which the ratio of hypointensity in the SW image relative to the size of the tumor was used to grade cerebral neoplasms. Hypointensity ratios closely correlated with the World Health Organization (WHO) grading scale of brain tumors and were more accurate than other grading schemes tested, such as the ITSS grading. However, hypointensity ratios represent a semiquantitative method that is ultimately limited by the subjectivity of intra- and interobserver discrepancies in score assignment. ${ }^{25}$

Di Ieva et al. ${ }^{25}$ have shown a computational fractalbased method applied to SWI analysis as an alternative glioma grading method. The geometric complexity of intratumoral SWI patterns resulting from intratumoral microbleedings and neoplastic vasculature and quantified by means of computational fractal-based analysis was shown to be related to the WHO glioma grade (Fig. 7)..$^{25}$ These results suggest that fractal analysis in SWI is a promising method in objective tumor grading since the fractal dimension value is a reliable and useful morphometric image marker to distinguish between low- and high-grade gliomas, ${ }^{24,25}$ as well as other brain tumors, such as brain metastases, meningiomas, and lymphomas (Di Ieva et al., unpublished data, 2015).

Although there is no consensus on tumor grading using SWI, the mentioned studies have demonstrated the potential value of SWI in that context as well as the possibility 

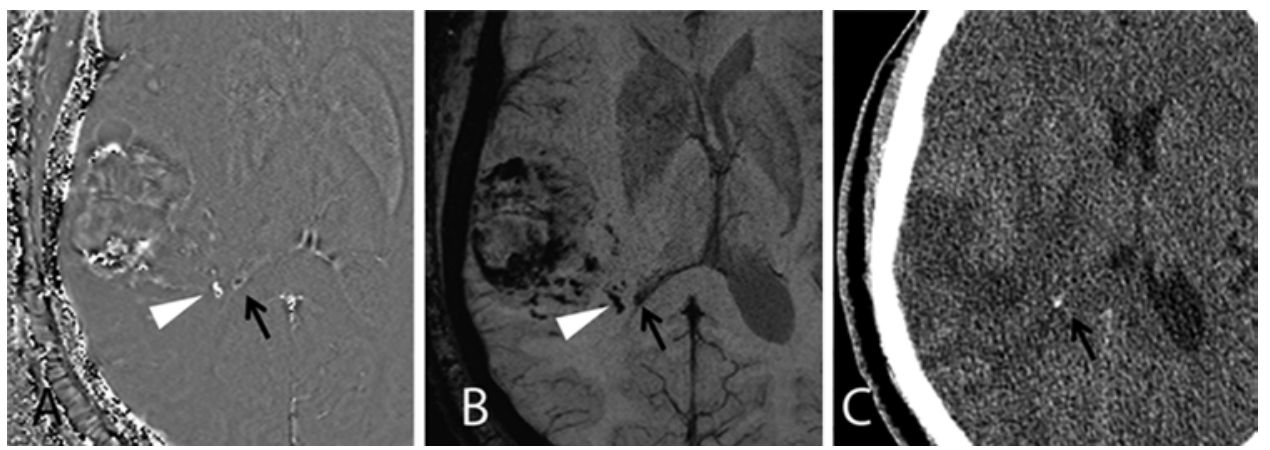

FIG. 5. Images obtained in a patient affected by GBM with extensive hemorrhage and large vessels. A: Filtered phase image showing hyperintense hemorrhage (white arrowhead) and hypointense calcium (black arrow) in the right choroid plexus. This applies for a left-handed system where veins and blood products show as hypointense (positive phase) and calcifications shows as hyperintense (negative phase). B: SW image shows hypointense foci corresponding to calcified choroid plexus (black arrow) and hemorrhage (white arrowhead). C: CT scan showing choroid plexus calcification.

of developing an objective grading technique with SWI for clinical applications.

In conclusion, SWI provides unique information in patients with brain tumors that cannot be obtained with other MRI sequences. A regular T2 GRE sequence can reveal the presence of hemorrhage or calcium, but it is less sensitive than SWI. Furthermore, SWI can differentiate between calcium and hemorrhage, which is not possible using any other MRI sequences. ${ }^{113}$ The distinction between the 2 types of imaging protocols (that is, SWI vs other MRI sequences, such as T2 GRE) is a key point in the differential diagnosis of brain tumors. Other advanced MRI techniques, such as perfusion MRI, may provide better information about microvessel density than SWI; however, perfusion MRI always requires interpretation by taking into account the presence of a susceptibility artifact. The presence of calcium or hemorrhage within the tumor leads to marked cerebral blood volume underestimation; therefore, SWI must be carefully evaluated before interpreting perfusion results. ${ }^{109}$

\section{Brain Tumor Follow-Up and Response to Treatment}

Several studies have demonstrated that SWI can be applied longitudinally to track tumor progression. Prior to treatment, the success of a patient's response to con-
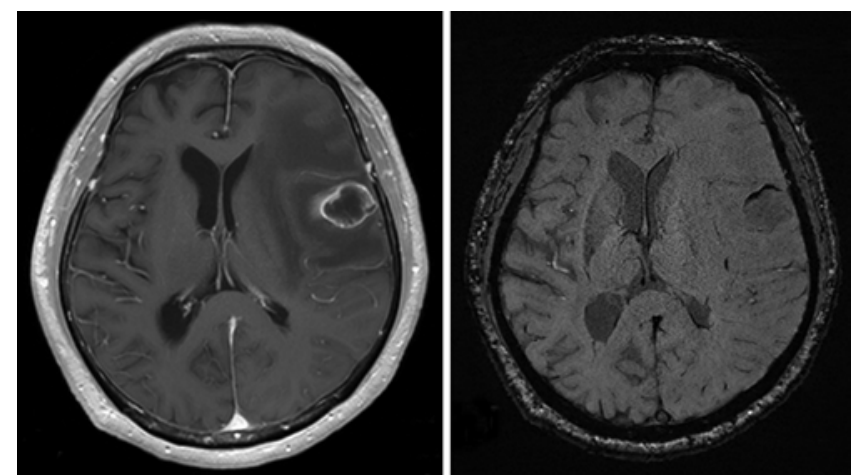

FIG. 6. Images obtained in a patient with metastatic carcinoma. Axial T1-weighted MR image post-Gd administration shows ring-enhancing lesion in the left frontal lobe with extensive surrounding edema (left). Axial SW image shows hemosiderin deposition along the anterior wall of the mass (right). comitant therapy, including radiotherapy, chemotherapy, and antiangiogenic drugs, can be predicted based on the percentage of SWI hypointensity volume in a T1-weighted contrast-enhancing lesion, in which higher percentages of SWI hypointensity volumes from a contrast-enhancing lesion correspond with a better response to concomitant therapy in patients with newly diagnosed GBM. ${ }^{72}$ Patient response to bevacizumab, an angiogenesis inhibitor, could be monitored with SWI to assess whether therapy produced favorable (decreased intratumoral microvasculature) or unfavorable (increased intratumoral microvasculature and the presence of cerebral microbleeds [CMBs]) results. ${ }^{26,37}$ In addition, SWI can detect radiation injury by monitoring the prevalence of CMBs after radiation therapy in patients with glioma ${ }^{12,71,115}$ or medulloblastoma. ${ }^{87}$ Currently, the focus is to develop and validate objective clinical measures, such as $\mathrm{PQ}^{89}$ and fractal analysis, ${ }^{26}$ to reduce the intra- and interobserver variability when assessing a tumor's current state and progression over time.

\section{SWI in Vascular Neurosurgery}

Cerebral vascular malformations (VMs) are disorders characterized by disruptions to normal brain vasculature, which could lead to hemorrhage or capillary function loss. ${ }^{107}$ SWI can aid in more accurate detection of the thrombotic region in stroke patients and help depict, differentiate, and monitor abnormal venous flow systems in patients with VMs. The role of SWI in stroke and VMs has been investigated in several studies. ${ }^{6,720,21,28 \text {, }}$ $29,31,48,49,52,53,56,57,59,62,64,69,88,93,97,110$

\section{Thrombosis Detection}

The cortical vessel sign (CVS) can determine the region of thrombosis by comparing the level of deoxygenated hemoglobin to oxygenated hemoglobin in a vessel of the affected hemisphere with vessels in the contralateral hemisphere. ${ }^{7,59}$ SWI can effectively determine the CVS to detect arterial occlusion ${ }^{49}$ and the change in CVS preand postadministration of the thrombolytic agent to assess reperfusion levels.? Although CVS measurements offer precise information on the thrombotic region, a simpler detection method involves the presence of dilated and hypointense cortical vessels on SW images ${ }^{97}$ The dilated 


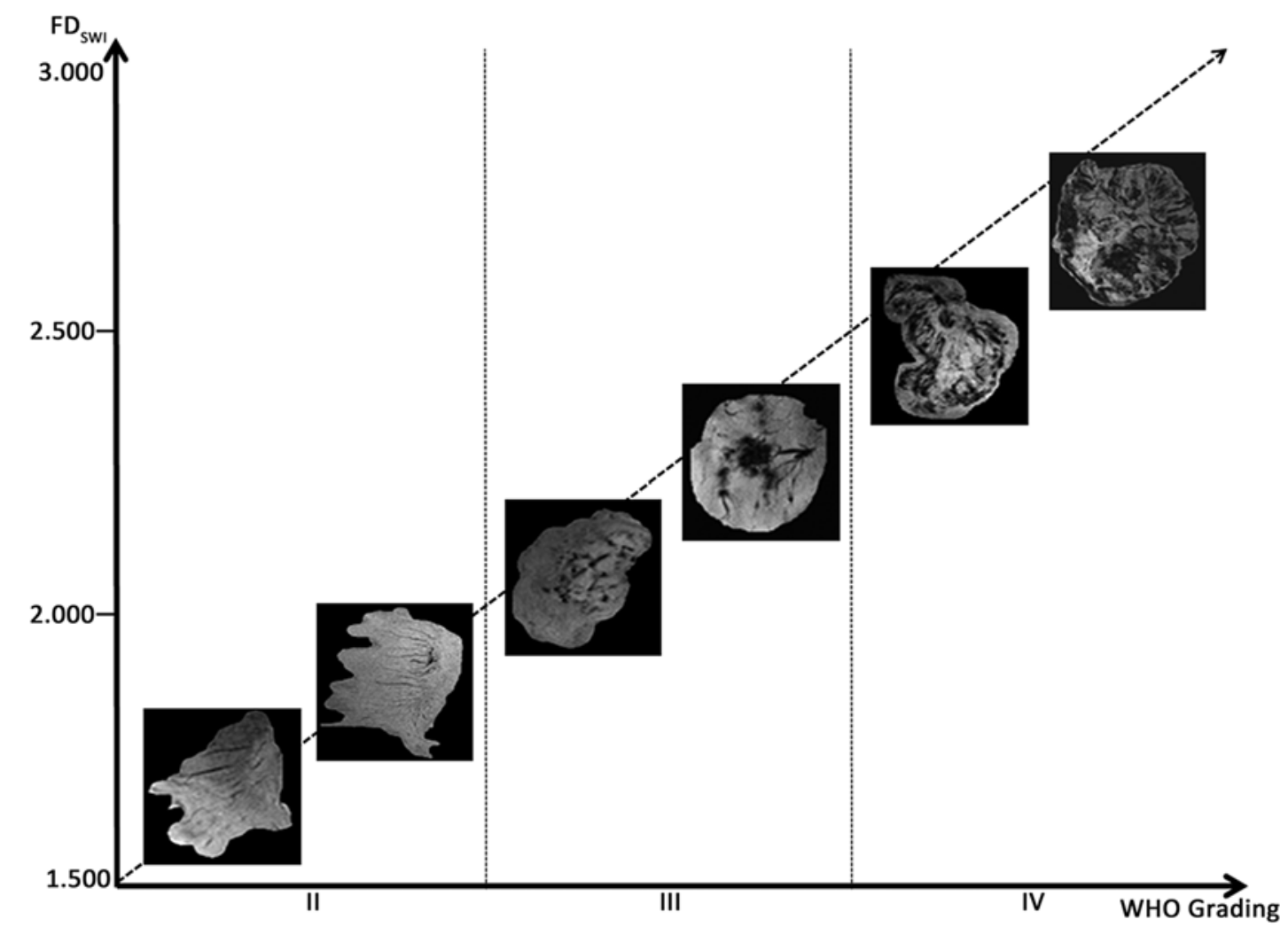

FIG. 7. Gliomas with different WHO grades (II, III, and IV). The intratumoral SWI patterns consist of distinct vascular structures (linear structures in Grade II gliomas, increasing in tortuosity and density in higher-grade gliomas) and conglomerated dot shapes, which most likely indicate intralesional bleeding and/or necrotic areas (as evident in Grade III and IV gliomas). The fractal dimension ( $F D_{\text {SWI }}$, on the $y$-axis) quantifies the level of geometric complexity of SWI patterns, with higher values found in groups of higher histopathological tumor grades. Reprinted from Springer/Neuroradiology 55, 2013, pp 35-40, Three-dimensional susceptibility-weighted imaging at $7 \mathrm{~T}$ using fractal-based quantitative analysis to grade gliomas, Di leva et al., Fig. 2. With kind permission from Springer Science and Business Media. Caption for this figure in the original source: "Schema showing the trend of higher FDswI values in groups of higher histopathological tumor grades. The intralesional SWI patterns consist of distinct vascular structures (linear structures in grade II tumors, increasing in tortuosity and density in higher grades gliomas) and conglomerated dot shapes, which most likely indicate intralesional bleeding and/or necrotic areas (as evident in grades III and IV gliomas). It should be noted that the images in the schema are only selections of the whole stack of axial sections of the tumor. However, the fractal dimension was measured with the volume of the three-dimensional reconstruction of the whole tumor."

region on SWI correlates with MR angiography (MRA) findings ${ }^{93}$ and could be used to monitor occlusion, ${ }^{57}$ along with the possibility for hemorrhagic transformation, ${ }^{57,64}$ over time.

\section{Monitoring Outcome in Stroke}

A limited collection of studies has examined the ability of SWI to monitor outcome in stroke patients; $;, 7,49,56,64$ however, the method of monitoring stroke outcome has varied greatly between studies. Bai et al. ${ }^{6}$ have suggested that a greater amount of CMBs on SWI after reperfusion is predictive of a better outcome. Despite this method's simplicity, it has several gaps. Considering that the presence of a CMB typically indicates brain injury, the idea of increased CMBs indicating a better outcome appears questionable. Furthermore, Bai et al. ${ }^{6}$ do not provide the range of CMBs that should be found on SW images after reperfusion, which causes ambiguity in determining whether a specific threshold of CMBs should be present on SW images or if the simple appearance of CMBs, regardless of the amount, is indicative of a good outcome.
Mismatches between SWI and DWI is another prognostic marker for stroke, ${ }^{56}$ which is based on a technique involving perfusion-weighted imaging (PWI)-DWI mismatches. Considering that PWI-DWI mismatches are still not clearly defined in the neuroradiological field,$^{13}$ it is likely that SWI-DWI mismatches would also pose problems of definition since the basis of the SWI-DWI mismatch technique would also be arbitrary among neuroradiologists. Nonetheless, the SWI-DWI mismatch has been recently shown to be a reliable marker for evaluating the ischemic penumbra in stroke patients with cerebral infarction. ${ }^{69}$

Measuring changes in the CVS over time was also examined as a potential approach toward stroke outcome prediction; however, no consensus exists regarding its validity. ${ }^{7,49}$ By monitoring changes in pre- and postrecanalization of the CVS, SWI can detect differences in CVS prominence before and after occlusion. ${ }^{7}$ Thus, an equal CVS postrecanalization (that is, the appearance of similar veins in both hemispheres) is suggestive of a good clinical outcome, whereas a less prominent CVS (that is, veins in an occluded hemisphere are less prominent than veins in 
an unaffected hemisphere) indicates a poor clinical outcome.

\section{Detection of VMs}

SWI has been reported to be more sensitive in detecting VMs than other imaging modalities, including $\mathrm{T} 1,{ }^{28}$ contrast-enhanced $\mathrm{T} 1,{ }^{48} \mathrm{~T} 2,{ }^{23,28} \mathrm{~T} 2 *, 20,23,88$ and FLAIR. ${ }^{28}$ However, most studies ${ }^{20,23,88}$ have focused on lesion detection in sporadic or familial cerebral cavernous malformations (CCMs), making it difficult to assess the sensitivity of SWI in detecting VMs other than CCMs.

As in T2* MRI, the difference between sporadic and familial CCM on SWI is the appearance of one lesion versus numerous lesions, respectively (Fig. 8). ${ }^{20}$ The Zabramski classification ${ }^{114}$ is a common system used to identify familial CCMs based on 4 types of lesion patterns seen in T1, T2, and GRE images. One study ${ }^{21}$ has attempted to match findings on SW images with the Zabramski classification; however, this approach requires further research as numerous lesions could not be classified into distinct categories for the GRE images.

Current research suggests that SWI may become an effective method for VM detection. SWI can distinguish high-flow from low-flow VMs. ${ }^{52,53}$ Moreover, in more complex cases, SWI can help diagnose specific high-flow VMs, such as arteriovenous malformations (AVMs; Fig. 9), ${ }^{53}$ and low-flow VMs, including CCM, 20,23,88 brain capillary telangiectasia, ${ }^{28}$ or Sturge-Weber syndrome. ${ }^{48,110}$ Most importantly, the findings from SWI, especially at ultrahigh fields (that is, $7 \mathrm{~T}$ ), ${ }^{29}$ are shown to correlate with histopathological studies. ${ }^{88} \mathrm{SWI}$ is a promising technique since its findings correlate well with "gold-standard" techniques for detecting VMs, including digital subtraction angiography and time-of-flight MRA. ${ }^{52}$ However, SWI in its present state cannot replace contrast-enhanced imaging, as the cortical venous reflex in dural arteriovenous fistulas appears to be missing ${ }^{62}$ while leptomeningeal abnormalities in SturgeWeber syndrome are not clearly depicted on SWI. ${ }^{48}$

\section{SWI in Neurotraumatology}

SWI is an effective imaging method that can detect microhemorrhage in the white matter of patients with traumatic brain injury (TBI) ${ }^{4,42}$ and can help dichotomize

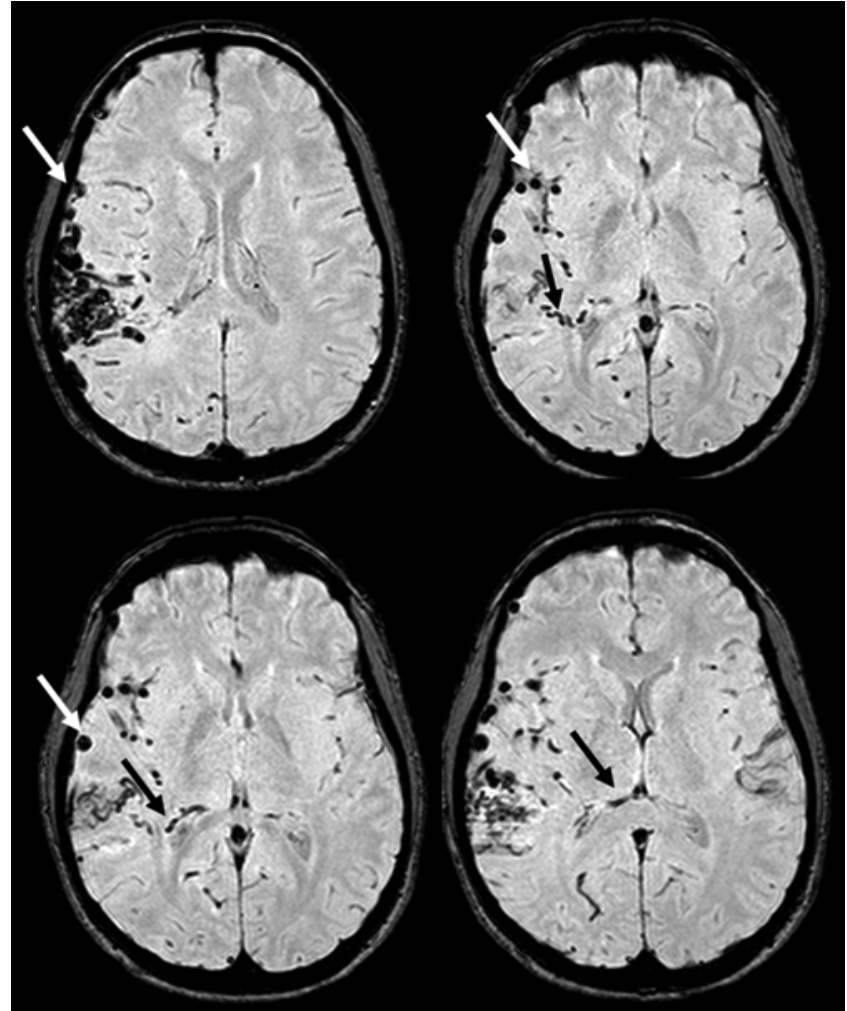

FIG. 9. SWI sequence showing a right temporoparietal AVM with superficial venous drainage and associated enlargement of cortical veins (white arrows). Deep venous drainage is demonstrated with an enlarged tortuous venous structure (black arrow) connecting a right subependymal vein, which drains into the right internal cerebral vein.

patients with diffuse axonal injury (DAI) as hemorrhagic or nonhemorrhagic. ${ }^{101}$ The ability to distinguish hemorrhagic from nonhemorrhagic DAI is beneficial since treatment, outcome, and prognosis will differ between these 2 conditions. In the last few years, several articles have been published on the application of SWI in patients with TBI. . $5,9,10,15,17,18,33,45,46,51,58,82,94,95,99-101$

\section{Lesion Detection}

Small punctate lesions seen on MR images are sugges-
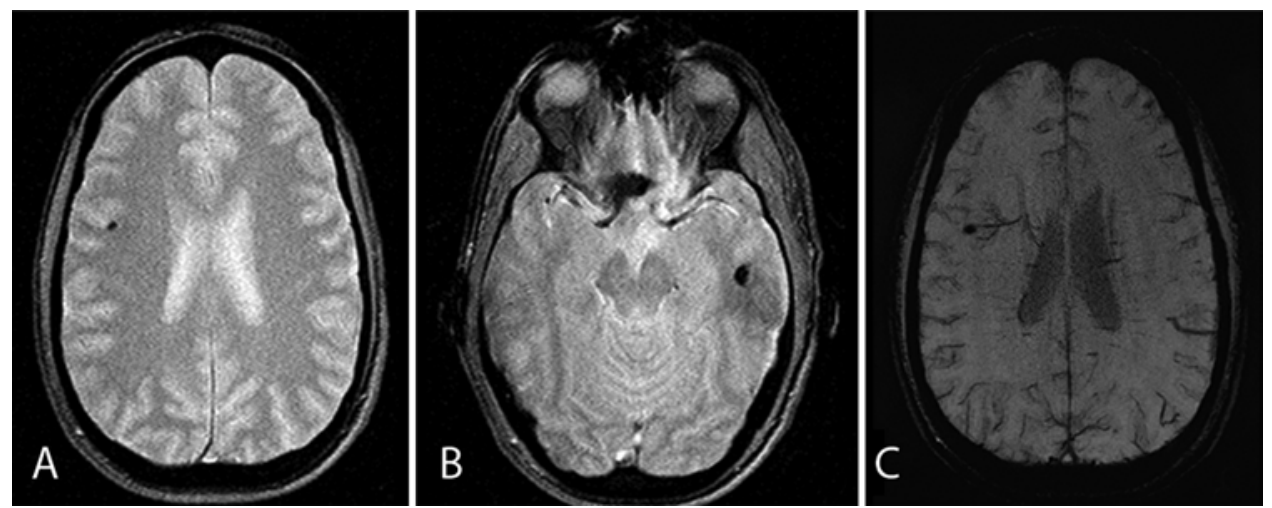

FIG. 8. Images obtained in a patient with nonspecific hypointense lesions. A and B: Axial T2 GRE sequences show both hypointense lesions. C: Axial SW image with mIP reformat demonstrates a developmental venous anomaly adjacent to the right frontal lesion, which suggests the diagnosis of cavernoma. 
tive of $\mathrm{DAI}^{32}$ and are commonly found in the brainstem and corpus callosum in postmortem analyses. ${ }^{2}$ Numerous studies have shown the sensitivity of SWI in lesion detection compared with other imaging techniques, including $\mathrm{CT}, 10,15,94 \mathrm{~T} 2,{ }^{10,15,33,45,94} \mathrm{~T} 2 * 3,33,45,100$ and FLAIR sequences. ${ }^{15,33,94,95}$ The high sensitivity of SWI allows for the detection and monitoring of smaller $(<5 \mathrm{~mm}) \mathrm{CMBs}^{46} \mathrm{In}$ particular, SWI is more sensitive in detecting lesions in the brainstem and corpus callosum, , 17,33,45,82,100 thereby providing neurosurgeons with more information on the extent of injury, ${ }^{94}$ which in turn helps to better predict edema and infarction, ${ }^{100}$ which is useful for prognostication. In essence, the mere presence of lesions in the brainstem and corpus callosum on SW images correlates with neuropathological findings outlined by Adams et al. ${ }^{2}$ The ability of SWI to match pathological findings in DAI lends credibility to the technique and suggests that it can be a necessary and sufficient imaging modality to diagnose DAI.

Although SWI can detect a global increase in brain lesions, it is more significant that the number and volume of these lesions correlate with Glasgow Coma Scale (GCS) scores $^{9,18,33,82,99}$ (Fig. 10). In particular, brainstem lesions correlate well with both GCS scores and the presentation of neurological deficits, including consciousness, disorientation, and visual field disturbances. ${ }^{51,82}$

\section{Outcome Prediction}

Various studies have demonstrated the effectiveness of SWI in outcome prediction using SWI for hemorrhage grading, ${ }^{51}$ the dichotomization of patients with and those without $\mathrm{CMBs},{ }^{29,33}$ or the detection of a greater number and volume of lesions. ${ }^{5,994,95,99}$ Despite having various SWI methods for outcome prediction, the current state of research has yet to reveal which method would exhibit the highest accuracy and specificity in predicting outcome and recovery.

In terms of outcome prediction with respect to clinical variables, such as surgical intervention and length of intubation, the number and volume of lesions detected on SWI was positively correlated with clinical severity. ${ }^{9}$ Lesion number and volume on SWI have respectable accuracy (approximately 78\%) when predicting outcome; however, the combination of clinical variables, such as GCS scores and coma duration, with SWI information provided an additive effect with higher accuracy and fewer false-positives and false-negatives in general than the use of either clinical variables or SWI data alone.${ }^{99}$ Another study showcasing the importance of combining information for better outcome prediction involved the use of SWI with FLAIR to predict clinical variables, such as time spent in the intensive care unit and total number of days of hospitalization, in children.${ }^{17}$ More specifically, patients with lesions on both SWI and FLAIR typically had poorer outcomes than patients with lesions found solely on SWI. ${ }^{17}$

Although these studies offer promising evidence for outcome prediction using SWI, an overarching limitation is the lack of consensus in defining "outcome." Most studies assessed neurological status using either the Glasgow Outcome Scale ${ }^{15,51,82,99}$ or Pediatric Cerebral Performance Category Scale (PCPCS). ${ }^{18,94}$ There is preliminary evidence that SWI is useful in predicting outcome through cognitive factors as well, including IQ, attention, and verbal reasoning. ${ }^{5,995}$ Finally, one study ${ }^{5}$ has reported that lesions to the brainstem and basal ganglia hold the strongest predictive power in determining neuropsychological outcome.

Although SWI is effective in outcome prediction, it is important to acknowledge that this imaging technique, in its current state, can only act as a complementary tool. The best predictor still involves clinical variables; ${ }^{5,18,58}$ however, SWI could become the next best predictor when clinical variables, such as coma duration, are difficult to assess. ${ }^{5}$

\section{SWI in Functional Neurosurgery}

SWI can effectively assist the neurosurgeon in providing more information for anatomical localization in functional neurosurgery, thereby providing safer and more efficient procedures for deep brain stimulation (DBS), ${ }^{1,74,80}$ as well as for Gamma Knife radiosurgery (for example, targeting nuclei of the thalamus for tremor treatment). ${ }^{102}$ The potential advantages of SWI in DBS and Gamma Knife radiosurgery, among other procedures, have led to a significant number of studies further examining the role of SWI in applications for functional neurosurgery. $1,14,22,39,43,44,55,66,74,80,91,103,106,116$

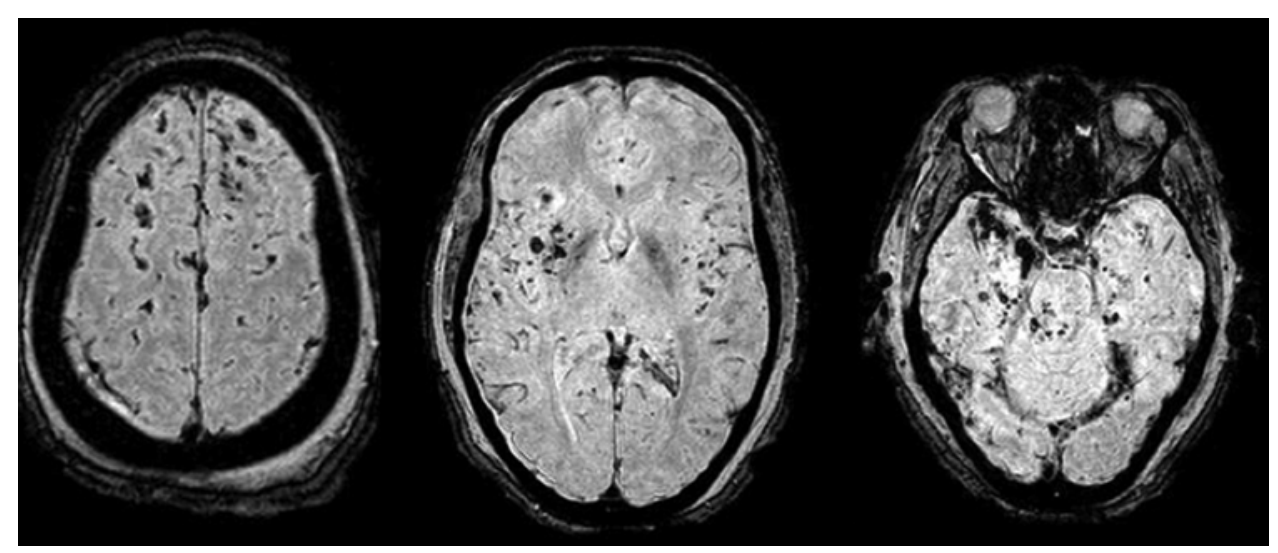

FIG. 10. Representative case of severe TBI in a 22-year-old patient who suffered a motor vehicle collision, GCS Score 3 on admission, in which SWI revealed diffuse bleeding in the white-gray matter junction, corona radiata, centrum semiovale, basal ganglia, and brainstem. The microbleedings in the brainstem were not visualized on CT and other MRI sequences. 


\section{Deep Brain Stimulation}

DBS works by targeting specific nuclei of the basal ganglia, such as the subthalamic nucleus (STN) or internal globus pallidus (GPi). ${ }^{61}$ DBS surgery requires MRI-guided stereotactic localization, microelectrode mapping, and intraoperative testing to determine optimal voltage thresholds ${ }^{96}$ Complications can arise when coordinates obtained from MR images and atlas mapping do not correspond, leading to malpositioning of electrodes ${ }^{85} \mathrm{SWI}$ can be used to clearly visualize the red nucleus, ${ }^{103}$ substantia nigra (SN), globus pallidus (GP), subthalamic nucleus (STN), ${ }^{1}$ along with various brainstem nuclei, such as the inferior olive and spinal trigeminal nucleus ${ }^{22}$ (based on differential iron deposition), which can assist in presurgical planning and diagnostic purposes. The ability of SWI to depict the venous network around the brainstem will provide neurosurgeons with even more information to plan surgical approaches in the infratentorial regions, as well as decide the final placement of electrodes, which can help prevent intracerebral hemorrhage..$^{14,71}$

Imaging of healthy volunteers and patients requiring DBS showed that SWI, relative to T1, T2, T2*, and PDweighted imaging, was most effective in depicting the STN. ${ }^{80}$ SWI using ultrahigh magnetic fields (7 T) can provide even greater contrast between midbrain structures, allowing for differentiation between internal and external portions of the globus pallidus (GPi and GPe), along with the development of 3D SWI maps outlining the location of the SN, STN, GPi, and GPe, which can aid in electrode placement and stimulation management. ${ }^{1}$ The benefits of applying SWI at $7 \mathrm{~T}$ are further observed with the delineation of blood vessels of varying sizes, including small venules as thin as $250 \mu \mathrm{m}^{77}$ and submillimeter cerebellar veins such as the central vein of the dentate nucleus. ${ }^{27}$

\section{Limitations of SWI}

Although SWI has been shown to be superior to conventional MRI in vessel imaging and hemorrhagic detection, the technique still has some limitations. Several studies have described the long acquisition times required to obtain an SW image, ${ }^{15,31,33,50,57,65,66,80,92,99,100,115}$ which makes movement artifacts likely to occur because of patient discomfort, which subsequently distorts SWI findings. ${ }^{31,57,92,100}$ The use of higher magnetic fields in SWI protocols at $3 \mathrm{~T}$ or $7 \mathrm{~T}^{15}$ and the application of parallel acquisition when obtaining SWI data are promising methods suggested to greatly reduce the required imaging time; ${ }^{31,92,99}$ however, further reduction in acquisition times remains a major priority.

SWI is prone to air-tissue artifacts with phase data ${ }^{22,50,92,}$ ${ }^{108,111}$ and susceptibility artifacts, such as bone structures, ${ }^{105}$ which can distort image findings. Furthermore, the sliceby-slice method, which neuroradiologists and computer programs use in counting the number of lesions found in SW images, may lead to an exaggeration of the number of lesions or a misinterpretation of blood vessels as lesions, spanning over many slices. ${ }^{100,108}$

Few studies have examined the relationship between SWI findings and histopathology. Lesions found on SWI can only be assumed to represent $\mathrm{CMBs}^{4,18,28}$ as verification from current histopathological studies is lacking. The small number of studies ${ }^{37,79,92,115}$ that have examined the link between these 2 variables have shown SWI confirming the results of histopathological analysis; however, findings have been limited to cerebral neoplasms. In some cases, correlations between SWI findings and histopathology are unlikely to be achieved given the benign nature of the disease, such as brain capillary telangiectasia, and biopsies will rarely be done to confirm SWI findings. ${ }^{28}$ However, in other cases in which the disease is fatal, it is important to verify the findings seen on SWI as lesions assumed to be CMBs could just as well represent cerebrovascular disease, hemorrhagic microangiopathy due to aging, or even fat. ${ }^{20,38}$

\section{Conclusions and Future Perspectives}

Although great advances have been made since the introduction of SWI, ${ }^{41}$ there are still many aspects in which SWI can improve and many fields in which SWI's applications can expand. Developing baselines ${ }^{111}$ and recording
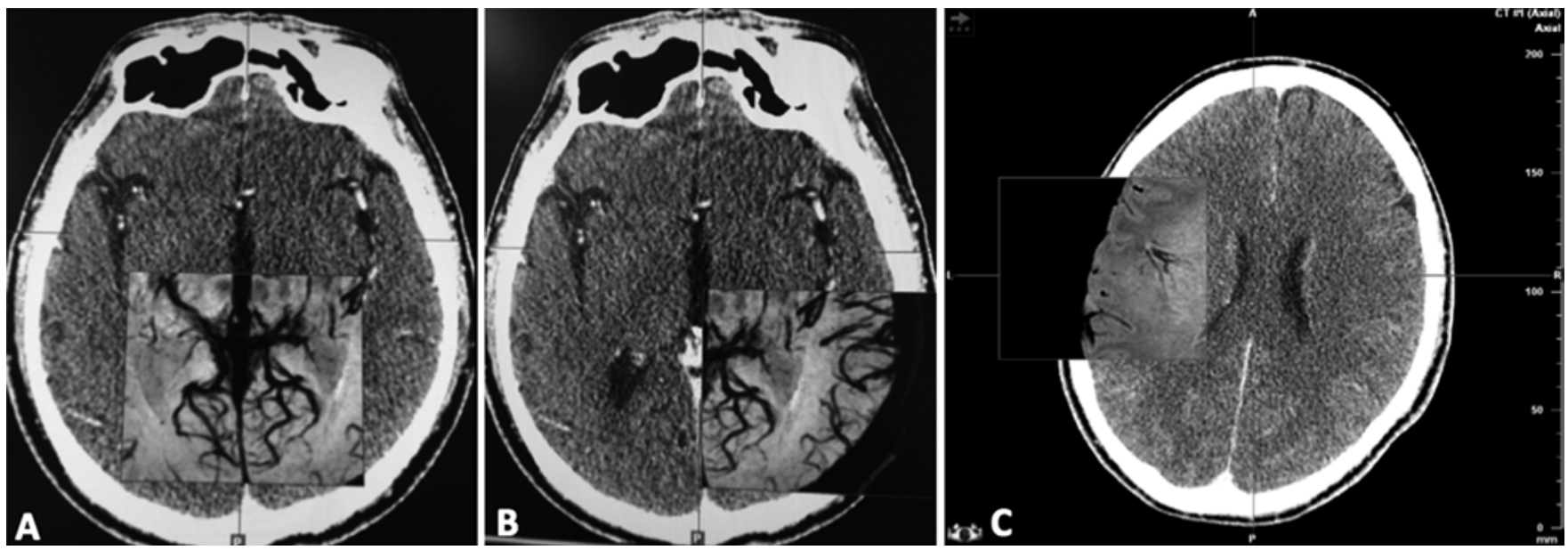

FIG. 11. Examples of the intraoperative fusion of SW images with CT scans for neuronavigational purposes, enhancing the CT data with venous structural information (A and B). A case of Grade II insular glioma (C). Frameless stereotactic biopsy planned with the fusion of SWI onto CT, allowing better planning of the trajectory to avoid intra- and extratumoral vasculature. 
isointensity values with respect to tumors or anatomical structures from SW images, such as the SN or GP, can help monitor disease states over time. Future SWI research should aim to decrease the intra- and interobserver variability in tumor boundary determination using objective measures, such as fractal analysis, as well as correlate histological findings with SWI data. ${ }^{24,26}$ Finally, research should focus on standardizing postprocessing procedures of SW images and correlating neuroradiological results with clinical symptoms to determine biomarkers helpful for prognosis. ${ }^{24,26}$

In essence, SWI is not limited to lesion detection but can be applied toward demonstrating treatment response in neurooncology, monitoring stroke recovery in vascular neurosurgery, and predicting outcomes in neurotraumatology, as well as better anatomical localization in functional neurosurgery and Gamma Knife radiosurgery. SW images can be fused in intraoperative neuronavigation as well, giving more intraoperative details on the venous vasculature, offering more information for stereotactic biopsies and planning of surgical approaches (Fig. 11). Neurosurgeons must be aware of the pros and cons of such a technique, adding it to their armamentarium whenever required. Advances in SWI research will eventually expand the role of SWI in neurosurgery.

\section{References}

1. Abosch A, Yacoub E, Ugurbil K, Harel N: An assessment of current brain targets for deep brain stimulation surgery with susceptibility-weighted imaging at 7 tesla. Neurosurgery 67:1745-1756, 2010

2. Adams JH, Doyle D, Ford I, Gennarelli TA, Graham DI, McLellan DR: Diffuse axonal injury in head injury: definition, diagnosis and grading. Histopathology 15:49-59, 1989

3. Akiyama Y, Miyata K, Harada K, Minamida Y, Nonaka T, Koyanagi I, et al: Susceptibility-weighted magnetic resonance imaging for the detection of cerebral microhemorrhage in patients with traumatic brain injury. Neurol Med Chir (Tokyo) 49:97-99, 2009

4. Ashwal S, Wycliffe ND, Holshouser BA: Advanced neuroimaging in children with nonaccidental trauma. Dev Neurosci 32:343-360, 2010

5. Babikian T, Freier MC, Tong KA, Nickerson JP, Wall CJ, Holshouser BA, et al: Susceptibility weighted imaging: neuropsychologic outcome and pediatric head injury. Pediatr Neurol 33:184-194, 2005

6. Bai Q, Zhao Z, Sui H, Xie X, Chen J, Yang J, et al: Susceptibility-weighted imaging for cerebral microbleed detection in super-acute ischemic stroke patients treated with intravenous thrombolysis. Neurol Res 35:586-593, 2013

7. Baik SK, Choi W, Oh SJ, Park KP, Park MG, Yang TI, et al: Change in cortical vessel signs on susceptibility-weighted images after full recanalization in hyperacute ischemic stroke. Cerebrovasc Dis 34:206-212, 2012

8. Bauer S, Wiest R, Nolte LP, Reyes M: A survey of MRIbased medical image analysis for brain tumor studies. Phys Med Biol 58:R97-R129, 2013

9. Beauchamp MH, Beare R, Ditchfield M, Coleman L, Babl FE, Kean M, et al: Susceptibility weighted imaging and its relationship to outcome after pediatric traumatic brain injury. Cortex 49:591-598, 2013

10. Beauchamp MH, Ditchfield M, Babl FE, Kean M, Catroppa $\mathrm{C}$, Yeates $\mathrm{KO}$, et al: Detecting traumatic brain lesions in children: CT versus MRI versus susceptibility weighted imaging (SWI). J Neurotrauma 28:915-927, 2011

11. Beggs CB, Shepherd SJ, Dwyer MG, Polak P, Magnano C, Carl E, et al: Sensitivity and specificity of SWI venography for detection of cerebral venous alterations in multiple sclerosis. Neurol Res 34:793-801, 2012

12. Bian W, Hess CP, Chang SM, Nelson SJ, Lupo JM: Susceptibility-weighted MR imaging of radiation therapyinduced cerebral microbleeds in patients with glioma: a comparison between 3T and 7T. Neuroradiology 56:91-96, 2014

13. Butcher KS, Parsons MW, Davis S, Donnan G: PWI/DWI mismatch: better definition required. Stroke 34:e215-e216, 2003

14. Cai M, Zhang XF, Qiao HH, Lin ZX, Ren CG, Li JC, et al: Susceptibility-weighted imaging of the venous networks around the brain stem. Neuroradiology 57:163-169, 2015 [epub ahead of print October 18, 2014]

15. Chastain CA, Oyoyo UE, Zipperman M, Joo E, Ashwal S, Shutter LA, et al: Predicting outcomes of traumatic brain injury by imaging modality and injury distribution. $\mathbf{J}$ Neurotrauma 26:1183-1196, 2009

16. Chavhan GB, Babyn PS, Thomas B, Shroff MM, Haacke EM: Principles, techniques, and applications of T $2 *$-based MR imaging and its special applications. Radiographics 29:1433-1449, 2009

17. Choi JI, Kim BJ, Ha SK, Kim SH, Lim DJ, Kim SD: Comparison of subgroups based on hemorrhagic lesions between SWI and FLAIR in pediatric traumatic brain injury. Childs Nerv Syst 30:1011-1019, 2014

18. Colbert CA, Holshouser BA, Aaen GS, Sheridan C, Oyoyo U, Kido D, et al: Value of cerebral microhemorrhages detected with susceptibility-weighted MR Imaging for prediction of long-term outcome in children with nonaccidental trauma. Radiology 256:898-905, 2010

19. Craelius W, Migdal MW, Luessenhop CP, Sugar A, Mihalakis I: Iron deposits surrounding multiple sclerosis plaques. Arch Pathol Lab Med 106:397-399, 1982

20. de Champfleur NM, Langlois C, Ankenbrandt WJ, Le Bars E, Leroy MA, Duffau H, et al: Magnetic resonance imaging evaluation of cerebral cavernous malformations with susceptibility-weighted imaging. Neurosurgery 68:641-648, 2011

21. de Souza JM, Domingues RC, Cruz LC Jr, Domingues FS, Iasbeck T, Gasparetto EL: Susceptibility-weighted imaging for the evaluation of patients with familial cerebral cavernous malformations: a comparison with T2-weighted fast spin-echo and gradient-echo sequences. AJNR Am J Neuroradiol 29:154-158, 2008

22. Deistung A, Schäfer A, Schweser F, Biedermann U, Güllmar D, Trampel R, et al: High-resolution MR imaging of the human brainstem in vivo at 7 tesla. Front Hum Neurosci 7:710, 2013

23. Deistung A, Schweser F, Wiestler B, Abello M, Roethke M, Sahm F, et al: Quantitative susceptibility mapping differentiates between blood depositions and calcifications in patients with glioblastoma. PLoS ONE 8: 57924, 2013

24. Di Ieva A, Esteban FJ, Grizzi F, Klonowski W, MartínLandrove M: Fractals in the neurosciences, part II: clinical applications and future perspectives. Neuroscientist 21:3043, 2015

25. Di Ieva A, Göd S, Grabner G, Grizzi F, Sherif C, Matula C, et al: Three-dimensional susceptibility-weighted imaging at $7 \mathrm{~T}$ using fractal-based quantitative analysis to grade gliomas. Neuroradiology 55:35-40, 2013

26. Di Ieva A, Matula C, Grizzi F, Grabner G, Trattnig S, Tschabitscher M: Fractal analysis of the susceptibility weighted imaging patterns in malignant brain tumors during antiangiogenic treatment: technical report on four cases seri- 
ally imaged by $7 \mathrm{~T}$ magnetic resonance during a period of four weeks. World Neurosurg 77:e11-e21, 2012

27. Di Ieva A, Tschabitscher M, Galzio RJ, Grabner G, Kronnerwetter C, Widhalm G, et al: The veins of the nucleus dentatus: anatomical and radiological findings. Neuroimage 54:74-79, 2011

28. El-Koussy M, Schroth G, Gralla J, Brekenfeld C, Andres RH, Jung S, et al: Susceptibility-weighted MR imaging for diagnosis of capillary telangiectasia of the brain. AJNR Am J Neuroradiol 33:715-720, 2012

29. Frischer JM, Göd S, Gruber A, Saringer W, Grabner G, Gatterbauer B, et al: Susceptibility-weighted imaging at 7 T: Improved diagnosis of cerebral cavernous malformations and associated developmental venous anomalies. Neuroimage Clin 1:116-120, 2012

30. Fu JH, Chuang TC, Chung HW, Chang HC, Lin HS, Hsu SS, et al: Discriminating pyogenic brain abscesses, necrotic glioblastomas, and necrotic metastatic brain tumors by means of susceptibility-weighted imaging. Eur Radiol 25:1413-1420, 2015

31. Fujima N, Kudo K, Terae S, Hida K, Ishizaka K, Zaitsu Y, et al: Spinal arteriovenous malformation: evaluation of change in venous oxygenation with susceptibility-weighted MR imaging after treatment. Radiology 254:891-899, 2010

32. Gentry LR, Godersky JC, Thompson B: MR imaging of head trauma: review of the distribution and radiopathologic features of traumatic lesions. AJR Am J Roentgenol 150:663-672, 1988

33. Geurts BH, Andriessen TM, Goraj BM, Vos PE: The reliability of magnetic resonance imaging in traumatic brain injury lesion detection. Brain Inj 26:1439-1450, 2012

34. Go JL, Zee CS: Unique CT imaging advantages. Hemorrhage and calcification. Neuroimaging Clin N Am 8:541-558, 1998

35. Grabner G, Dal-Bianco A, Hametner S, Lassmann H, Trattnig S: Group specific vein-atlasing: an application for analyzing the venous system under normal and multiple sclerosis conditions. J Magn Reson Imaging 40:655-661, 2014

36. Grabner G, Dal-Bianco A, Schernthaner M, Vass K, Lassmann H, Trattnig S: Analysis of multiple sclerosis lesions using a fusion of 3.0 T FLAIR and 7.0 T SWI phase: FLAIR SWI. J Magn Reson Imaging 33:543-549, 2011

37. Grabner G, Nöbauer I, Elandt K, Kronnerwetter C, Woehrer A, Marosi C, et al: Longitudinal brain imaging of five malignant glioma patients treated with bevacizumab using susceptibility-weighted magnetic resonance imaging at $7 \mathrm{~T}$. Magn Reson Imaging 30:139-147, 2012

38. Gramsch C, Göricke SL, Behrens F, Zimmer L, Schadendorf D, Krasny A, et al: Isolated cerebral susceptibility artefacts in patients with malignant melanoma: metastasis or not? Eur Radiol 23:2622-2627, 2013

39. Gupta D, Saini J, Kesavadas C, Sarma PS, Kishore A: Utility of susceptibility-weighted MRI in differentiating Parkinson's disease and atypical parkinsonism. Neuroradiology 52:1087-1094, 2010

40. Haacke EM, Makki M, Ge Y, Maheshwari M, Sehgal V, Hu $\mathrm{J}$, et al: Characterizing iron deposition in multiple sclerosis lesions using susceptibility weighted imaging. J Magn Reson Imaging 29:537-544, 2009

41. Haacke EM, Mittal S, Wu Z, Neelavalli J, Cheng YCN: Susceptibility-weighted imaging: technical aspects and clinical applications, part 1. AJNR Am J Neuroradiol 30:19-30, 2009

42. Haacke EM, Xu Y, Cheng YC, Reichenbach JR: Susceptibility weighted imaging (SWI). Magn Reson Med 52:612-618, 2004

43. Haller S, Badoud S, Nguyen D, Barnaure I, Montandon ML, Lovblad KO, et al: Differentiation between Parkinson dis- ease and other forms of Parkinsonism using support vector machine analysis of susceptibility-weighted imaging (SWI): initial results. Eur Radiol 23:12-19, 2013

44. Han YH, Lee JH, Kang BM, Mun CW, Baik SK, Shin YI, et al: Topographical differences of brain iron deposition between progressive supranuclear palsy and parkinsonian variant multiple system atrophy. J Neurol Sci 325:29-35, 2013

45. Hasiloglu ZI, Albayram S, Selcuk H, Ceyhan E, Delil S, Arkan B, et al: Cerebral microhemorrhages detected by susceptibility-weighted imaging in amateur boxers. AJNR Am J Neuroradiol 32:99-102, 2011

46. Helmer KG, Pasternak O, Fredman E, Preciado RI, Koerte IK, Sasaki T, et al: Hockey Concussion Education Project, Part 1. Susceptibility-weighted imaging study in male and female ice hockey players over a single season. $\mathbf{J}$ Neurosurg 120:864-872, 2014

47. Hori M, Mori H, Aoki S, Abe O, Masumoto T, Kunimatsu $\mathrm{S}$, et al: Three-dimensional susceptibility-weighted imaging at $3 \mathrm{~T}$ using various image analysis methods in the estimation of grading intracranial gliomas. Magn Reson Imaging 28:594-598, 2010

48. Hu J, Yu Y, Juhasz C, Kou Z, Xuan Y, Latif Z, et al: MR susceptibility weighted imaging (SWI) complements conventional contrast enhanced T1 weighted MRI in characterizing brain abnormalities of Sturge-Weber Syndrome. J Magn Reson Imaging 28:300-307, 2008

49 Huang P, Chen CH, Lin WC, Lin RT, Khor GT, Liu CK: Clinical applications of susceptibility weighted imaging in patients with major stroke. J Neurol 259:1426-1432, 2012

50. Hunter JV, Wilde EA, Tong KA, Holshouser BA: Emerging imaging tools for use with traumatic brain injury research. J Neurotrauma 29:654-671, 2012

51. Iwamura A, Taoka T, Fukusumi A, Sakamoto M, Miyasaka T, Ochi T, et al: Diffuse vascular injury: convergent-type hemorrhage in the supratentorial white matter on susceptibility-weighted image in cases of severe traumatic brain damage. Neuroradiology 54:335-343, 2012

52. Jagadeesan BD, Cross DT III, Delgado Almandoz JE, Derdeyn CP, Loy DN, McKinstry RC, et al: Susceptibilityweighted imaging: a new tool in the diagnosis and evaluation of abnormalities of the vein of Galen in children. AJNR Am J Neuroradiol 33:1747-1751, 2012

53. Jagadeesan BD, Delgado Almandoz JE, Moran CJ, Benzinger TL: Accuracy of susceptibility-weighted imaging for the detection of arteriovenous shunting in vascular malformations of the brain. Stroke 42:87-92, 2011

54. Jenkinson MD, du Plessis DG, Smith TS, Joyce KA, Warnke PC, Walker C: Histological growth patterns and genotype in oligodendroglial tumours: correlation with MRI features. Brain 129:1884-1891, 2006

55. Jin L, Wang J, Jin H, Fei G, Zhang Y, Chen W, et al: Nigral iron deposition occurs across motor phenotypes of Parkinson's disease. Eur J Neurol 19:969-976, 2012

56. Kao HW, Tsai FY, Hasso AN: Predicting stroke evolution: comparison of susceptibility-weighted MR imaging with MR perfusion. Eur Radiol 22: 1397-1403, 2012

57. Kawabori M, Kuroda S, Kudo K, Terae S, Kaneda M, Nakayama N, et al: Susceptibility-weighted magnetic resonance imaging detects impaired cerebral hemodynamics in the superior sagittal sinus thrombosis-case report. Neurol Med Chir (Tokyo) 49:248-251, 2009

58. Keightley ML, Chen JK, Ptito A: Examining the neural impact of pediatric concussion: a scoping review of multimodal and integrative approaches using functional and structural MRI techniques. Curr Opin Pediatr 24:709-716, 2012

59. Kesavadas C, Santhosh K, Thomas B: Susceptibility weighted imaging in cerebral hypoperfusion-can we pre- 
dict increased oxygen extraction fraction? Neuroradiology 52: 1047-1054, 2010

60. Kim HS, Jahng GH, Ryu CW, Kim SY: Added value and diagnostic performance of intratumoral susceptibility signals in the differential diagnosis of solitary enhancing brain lesions: preliminary study. AJNR Am J Neuroradiol 30:1574-1579, 2009

61. Kumar R, Lozano AM, Montgomery E, Lang AE: Pallidotomy and deep brain stimulation of the pallidum and subthalamic nucleus in advanced Parkinson's disease. Mov Disord 13 (Suppl 1):73-82, 1998

62. Letourneau-Guillon L, Krings T: Simultaneous arteriovenous shunting and venous congestion identification in dural arteriovenous fistulas using susceptibility-weighted imaging: initial experience. AJNR Am J Neuroradiol 33:301307, 2012

63. Li C, Ai B, Li Y, Qi H, Wu L: Susceptibility-weighted imaging in grading brain astrocytomas. Eur J Radiol 75:e81-e85, 2010

64. Li M, Hu J, Miao Y, Shen H, Tao D, Yang Z, et al: In vivo measurement of oxygenation changes after stroke using susceptibility weighted imaging filtered phase data. PLoS ONE 8:e63013, 2013

65. Löbel U, Sedlacik J, Sabin ND, Kocak M, Broniscer A, Hillenbrand CM, et al: Three-dimensional susceptibilityweighted imaging and two-dimensional $\mathrm{T} 2 *$-weighted gradient-echo imaging of intratumoral hemorrhages in pediatric diffuse intrinsic pontine glioma. Neuroradiology 52: 1167-1177, 2010

66. Lotfipour AK, Wharton S, Schwarz ST, Gontu V, Schäfer A, Peters AM, et al: High resolution magnetic susceptibility mapping of the substantia nigra in Parkinson's disease. J Magn Reson Imaging 35:48-55, 2012

67. Lou X, Ma L, Wang FL, Tang ZP, Huang H, Cai YQ, et al: Susceptibility-weighted imaging in the diagnosis of early basal ganglia germinoma. AJNR Am J Neuroradiol 30:1694-1699, 2009

68. Lou X, Tian C, Chen Z, Ma L: Differential diagnosis of infarct-like intracranial ectopic germinomas and subacute lacunar infarct on susceptibility-weighted imaging. J Magn Reson Imaging 36:92-98, 2012

69. Luo S, Yang L, Wang L: Comparison of susceptibilityweighted and perfusion-weighted magnetic resonance imaging in the detection of penumbra in acute ischemic stroke. $\mathbf{J}$ Neuroradiol [epub ahead of print], 2014

70. Lupo JM, Banerjee S, Hammond KE, Kelley DA, Xu D, Chang SM, et al: GRAPPA-based susceptibility-weighted imaging of normal volunteers and patients with brain tumor at 7 T. Magn Reson Imaging 27:480-488, 2009

71. Lupo JM, Chuang CF, Chang SM, Barani IJ, Jimenez B, Hess CP, et al: 7-Tesla susceptibility-weighted imaging to assess the effects of radiotherapy on normal-appearing brain in patients with glioma. Int J Radiat Oncol Biol Phys 82:e493-e500, 2012

72. Lupo JM, Essock-Burns E, Molinaro AM, Cha S, Chang SM, Butowski N, et al: Using susceptibility-weighted imaging to determine response to combined anti-angiogenic, cytotoxic, and radiation therapy in patients with glioblastoma multiforme. Neuro Oncol 15:480-489, 2013

73. Maderwald S, Thürling M, Küper M, Theysohn N, Müller $\mathrm{O}$, Beck A, et al: Direct visualization of cerebellar nuclei in patients with focal cerebellar lesions and its application for lesion-symptom mapping. Neuroimage 63:1421-1431, 2012

74. Mahvash M, Pechlivanis I, Charalampaki P, Jansen O, Mehdorn HM: Visualization of small veins with susceptibility-weighted imaging for stereotactic trajectory planning in deep brain stimulation. Clin Neurol Neurosurg 124:151155,2014
75. Martin F Jr, Lemmen LJ: Calcification in intracranial neoplasms. Am J Pathol 28:1107-1131, 1952

76. Mittal S, Wu Z, Neelavalli J, Haacke EM: Susceptibilityweighted imaging: technical aspects and clinical applications, part 2. AJNR Am J Neuroradiol 30:232-252, 2009

77. Moenninghoff C, Kraff O, Schlamann M, Ladd ME, Katsarava Z, Gizewski ER: Assessing a dysplastic cerebellar gangliocytoma (Lhermitte-Duclos disease) with 7T MR imaging. Korean J Radiol 11:244-248, 2010

78. Mørk SJ, Lindegaard KF, Halvorsen TB, Lehmann EH, Solgaard T, Hatlevoll R, et al: Oligodendroglioma: incidence and biological behavior in a defined population. $\mathbf{J}$ Neurosurg 63:881-889, 1985

79. Nishiguchi T, Iwakiri T, Hayasaki K, Ohsawa M, Yoneda T, Mitsuhashi Y, et al: Post-embolisation susceptibility changes in giant meningiomas: multiparametric histogram analysis using non-contrast-enhanced susceptibility-weighted PRESTO, diffusion-weighted and perfusion-weighted imaging. Eur Radiol 23:551-561, 2013

80. O'Gorman RL, Shmueli K, Ashkan K, Samuel M, Lythgoe DJ, Shahidiani A, et al: Optimal MRI methods for direct stereotactic targeting of the subthalamic nucleus and globus pallidus. Eur Radiol 21:130-136, 2011

81. Ohmoto Y, Nishizaki T, Kajiwara K, Nomura S, Kameda H, Suzuki M: Calcified metastatic brain tumor-two case reports. Neurol Med Chir (Tokyo) 42:264-267, 2002

82. Park JH, Park SW, Kang SH, Nam TK, Min BK, Hwang SN: Detection of traumatic cerebral microbleeds by susceptibility-weighted image of MRI. J Korean Neurosurg Soc 46:365-369, 2009

83. Park MJ, Kim HS, Jahng GH, Ryu CW, Park SM, Kim SY: Semiquantitative assessment of intratumoral susceptibility signals using non-contrast-enhanced high-field high-resolution susceptibility-weighted imaging in patients with gliomas: comparison with MR perfusion imaging. AJNR Am J Neuroradiol 30:1402-1408, 2009

84. Park SM, Kim HS, Jahng GH, Ryu CW, Kim SY: Combination of high-resolution susceptibility-weighted imaging and the apparent diffusion coefficient: added value to brain tumour imaging and clinical feasibility of noncontrast MRI at 3 T. Br J Radiol 83:466-475, 2010

85. Patel NK, Khan S, Gill SS: Comparison of atlas- and magnetic-resonance-imaging-based stereotactic targeting of the subthalamic nucleus in the surgical treatment of Parkinson's disease. Stereotact Funct Neurosurg 86: 153-161, 2008

86. Peters S, Knöß N, Wodarg F, Cnyrim C, Jansen O: Glioblastomas vs. lymphomas: more diagnostic certainty by using susceptibility-weighted imaging (SWI). Rofo 184:713-718, 2012

87. Peters S, Pahl R, Claviez A, Jansen O: Detection of irreversible changes in susceptibility-weighted images after whole-brain irradiation of children. Neuroradiology 55:853-859, 2013

88. Pinker K, Stavrou I, Szomolanyi P, Hoeftberger R, Weber M, Stadlbauer A, et al: Improved preoperative evaluation of cerebral cavernomas by high-field, high-resolution susceptibility-weighted magnetic resonance imaging at 3 Tesla: comparison with standard $(1.5 \mathrm{~T})$ magnetic resonance imaging and correlation with histopathological findingspreliminary results. Invest Radiol 42:346-351, 2007

89. Radbruch A, Graf M, Kramp L, Wiestler B, Floca R, Bäumer P, et al: Differentiation of brain metastases by percentagewise quantification of intratumoral-susceptibilitysignals at 3Tesla. Eur J Radiol 81:4064-4068, 2012

90. Reichenbach JR, Venkatesan R, Schillinger DJ, Kido DK, Haacke EM: Small vessels in the human brain: MR venography with deoxyhemoglobin as an intrinsic contrast agent. Radiology 204:272-277, 1997

91. Rossi M, Ruottinen H, Elovaara I, Ryymin P, Soimakallio 
$\mathrm{S}$, Eskola $\mathrm{H}$, et al: Brain iron deposition and sequence characteristics in Parkinsonism: comparison of SWI, $\mathrm{T}_{2} *$ maps, $\mathrm{T}_{2}$-weighted-, and FLAIR-SPACE. Invest Radiol 45:795802,2010

92. Sehgal V, Delproposto Z, Haddar D, Haacke EM, Sloan AE, Zamorano LJ, et al: Susceptibility-weighted imaging to visualize blood products and improve tumor contrast in the study of brain masses. J Magn Reson Imaging 24:41-51, 2006

93. Shimoda Y, Kudo K, Kuroda S, Zaitsu Y, Fujima N, Terae $\mathrm{S}$, et al: Susceptibility-weighted imaging and magnetic resonance angiography during migraine attack: a case report. Magn Reson Med Sci 10:49-52, 2011

94. Sigmund GA, Tong KA, Nickerson JP, Wall CJ, Oyoyo U, Ashwal S: Multimodality comparison of neuroimaging in pediatric traumatic brain injury. Pediatr Neurol 36:217226, 2007

95. Spitz G, Maller JJ, Ng A, O'Sullivan R, Ferris NJ, Ponsford JL: Detecting lesions after traumatic brain injury using susceptibility weighted imaging: a comparison with fluidattenuated inversion recovery and correlation with clinical outcome. J Neurotrauma 30:2038-2050, 2013

96. Starr PA: Placement of deep brain stimulators into the subthalamic nucleus or Globus pallidus internus: technical approach. Stereotact Funct Neurosurg 79:118-145, 2002

97. Sun W, Yuan C, Liu W, Li Y, Huang Z, Zhu W, et al: Asymptomatic cerebral microbleeds in adult patients with moyamoya disease: a prospective cohort study with 2 years of follow-up. Cerebrovasc Dis 35:469-475, 2013

98. Toh CH, Wei KC, Chang CN, Hsu PW, Wong HF, Ng $\mathrm{SH}$, et al: Differentiation of pyogenic brain abscesses from necrotic glioblastomas with use of susceptibility-weighted imaging. AJNR Am J Neuroradiol 33:1534-1538, 2012

99. Tong KA, Ashwal S, Holshouser BA, Nickerson JP, Wall CJ, Shutter LA, et al: Diffuse axonal injury in children: clinical correlation with hemorrhagic lesions. Ann Neurol 56:36-50, 2004

100. Tong KA, Ashwal S, Holshouser BA, Shutter LA, Herigault G, Haacke EM, et al: Hemorrhagic shearing lesions in children and adolescents with posttraumatic diffuse axonal injury: improved detection and initial results. Radiology 227:332-339, 2003

101. Toth A, Kovacs N, Perlaki G, Orsi G, Aradi M, Komaromy $\mathrm{H}$, et al: Multi-modal magnetic resonance imaging in the acute and sub-acute phase of mild traumatic brain injury: can we see the difference? J Neurotrauma 30:2-10, 2013

102. Tuleasca C, Najdenovska E, Marques J, Vingerhoets F, Thiran J, Cuadra MB, et al: Targetting of the ventro-intermediate nucleus using ultra-high field (7T) MRI for gamma knife surgery purposes: A pilot in vivo study on healthy subjects. Neurochirurgie 60:347, 2014

103. Vossough A, Ziai P, Chatzkel JA: Red nucleus degeneration in hypertrophic olivary degeneration after pediatric posterior fossa tumor resection: use of susceptibility-weighted imaging (SWI). Pediatr Radiol 42:481-485, 2012

104. Walton JC, Kaufmann JC: Iron deposits and multiple sclerosis. Arch Pathol Lab Med 108:755-756, 1984

105. Wang M, Dai Y, Han Y, Haacke EM, Dai J, Shi D: Susceptibility weighted imaging in detecting hemorrhage in acute cervical spinal cord injury. Magn Reson Imaging 29:365-373, 2011

106. Wang Y, Butros SR, Shuai X, Dai Y, Chen C, Liu M, et al: Different iron-deposition patterns of multiple system atrophy with predominant parkinsonism and idiopathetic Parkinson diseases demonstrated by phase-corrected susceptibility-weighted imaging. AJNR Am J Neuroradiol 33:266-273, 2012

107. Whitehead KJ, Smith MC, Li DY: Arteriovenous malfor- mations and other vascular malformation syndromes. Cold Spring Harb Perspect Med 3:a006635, 2013

108. Wieczorek-Pastusiak J, Kociński M, Raźniewski M, Strzelecki M, Stefańczyk L, Majos A: An attempt toward objective assessment of brain tumor vascularization using susceptibility weighted imaging and dedicated computer program - a preliminary study. Pol J Radiol 78:50-56, 2013

109. Willats L, Calamante F: The 39 steps: evading error and deciphering the secrets for accurate dynamic susceptibility contrast MRI. NMR Biomed 26:913-931, 2013

110. Wu J, Tarabishy B, Hu J, Miao Y, Cai Z, Xuan Y, et al: Cortical calcification in Sturge-Weber Syndrome on MRISWI: relation to brain perfusion status and seizure severity. J Magn Reson Imaging 34:791-798, 2011

111. Wu Z, Li S, Lei J, An D, Haacke EM: Evaluation of traumatic subarachnoid hemorrhage using susceptibility-weighted imaging. AJNR Am J Neuroradiol 31:1302-1310, 2010

112. Wu Z, Mittal S, Kish K, Yu Y, Hu J, Haacke EM: Identification of calcification with MRI using susceptibilityweighted imaging: a case study. J Magn Reson Imaging 29:177-182, 2009

113. Yamada N, Imakita S, Sakuma T, Takamiya M: Intracranial calcification on gradient-echo phase image: depiction of diamagnetic susceptibility. Radiology 198:171-178, 1996

114. Zabramski JM, Wascher TM, Spetzler RF, Johnson B, Golfinos J, Drayer BP, et al: The natural history of familial cavernous malformations: results of an ongoing study. $\mathbf{J}$ Neurosurg 80:422-432, 1994

115. Zeng QS, Kang XS, Li CF, Zhou GY: Detection of hemorrhagic hypointense foci in radiation injury region using susceptibility-weighted imaging. Acta Radiol 52:115-119, 2011

116. Zhang J, Zhang Y, Wang J, Cai P, Luo C, Qian Z, et al: Characterizing iron deposition in Parkinson's disease using susceptibility-weighted imaging: an in vivo MR study. Brain Res 1330:124-130, 2010

117. Zhang W, Ma XX, Ji YM, Kang XS, Li CF: Haemorrhage detection in brain metastases of lung cancer patients using magnetic resonance imaging. J Int Med Res 37:1139-1144, 2009

118. Zulfiqar M, Dumrongpisutikul N, Intrapiromkul J, Yousem DM: Detection of intratumoral calcification in oligodendrogliomas by susceptibility-weighted MR imaging. AJNR Am J Neuroradiol 33:858-864, 2012

\section{Author Contributions}

Conception and design: Di Ieva. Acquisition of data: Di Ieva, Lam, Alcaide-Leon. Analysis and interpretation of data: Di Ieva, Lam, Bharatha. Drafting the article: Di Ieva, Lam. Critically revising the article: Di Ieva, Cusimano. Reviewed submitted version of manuscript: all authors. Approved the final version of the manuscript on behalf of all authors: Di Ieva. Administrative/technical/material support: Montanera, Cusimano. Study supervision: Di Ieva, Cusimano.

\section{Supplemental Information Current Affiliation}

Dr. Di Ieva: Macquarie University Hospital, Sydney, NSW, Australia.

\section{Correspondence}

Antonio Di Ieva, Division of Neurosurgery, St. Michael's Hospital, University of Toronto, 30 Bond St., Toronto, ON M5B 1W8, Canada.email: diieva@hotmail.com. 